\title{
Performance evaluation of a hybrid fuzzy logic controller based on genetic algorithm for three phase induction motor drive
}

\author{
Ahmed J. Ali ${ }^{1}$, Ziyad K. Farej ${ }^{2}$, Nashwan S. Sultan ${ }^{3}$ \\ ${ }^{1,3}$ Department of Power Technichal Engineering, Northern Technichal University, Iraq \\ ${ }^{2}$ Department of of Biomedical Engineering, Northern Technichal University, Iraq
}

\begin{tabular}{l}
\hline Article Info \\
\hline Article history: \\
Received Aug 29, 2018 \\
Revised Nov 7, 2018 \\
Accepted Dec 18, 2018 \\
\hline
\end{tabular}

Keywords:

Fuzzy logic controller Genetic algorithm Induction motor PID controller

\begin{abstract}
It is known that controlling the speed of a three phase Induction Motor (IM) under different operating conditions is an important task and this can be accomplished through the process of controlling the applied voltage on its stator circuit. Conventional Proportional- Integral- Differeantional (PID) controller takes long time in selecting the error signal gain values. In this paper a hybrid Fuzzy Logic Controller (FLC) with Genetic Algorithm (GA) is proposed to reduce the selected time for the optimized error signal gain values and as a result inhances the controller and system performance. The proposed controller FL with GA is designed, modeled and simulated using MATLAB/ software under different load torque motor operating condition. The simulation result shows that the closed loop system performance efficiency under the controller has a maximum value of $95.92 \%$. In terms of efficiency and at reference speed signal of $146.53 \mathrm{rad} / \mathrm{sec}$, this system performance shows an inhancement of $0.67 \%, 0.49 \%$ and $0.05 \%$ with respect to the closed loop system efficiency performance of the PID, FL, and PID with GA controllers respectively. Also the simulation result of the well designed and efficient GA in speeding up the process of selecting the gain values, makes the system to have an efficiency improvement of $14.42 \%$ with respect to the open loop system performance.
\end{abstract}

Copyright (c) 2019 Institute of Advanced Engineering and Science. All rights reserved.

\section{Corresponding Author:}

Ahmed J. Ali,

Department of Power Technichal Engineering,

Northern Technichal University, Iraq.

Email: ahmedem71@gmail.com

\section{INTRODUCTION}

Three-phase induction motors have a wide industrial applications due to their ability for working under different environmental operation conditions. Also the attractive features (such as high reliability, wide range of speed variation, low maintenance requirements and low cost) of these motors make them the preferred choice for customers. Different methods have been proposed to control motor speed according to its application importance. One of these simple and common method is to change the number of stator poles, so that speed value can be doubled, (in an increasing or decreasing matter). For the applications that require a wide range of speed factor variation, the applied voltage and frequency can be considered an efficient method. Different types of classical controller had been recycled to adjust the IM speed. PID controller is considered one of the most convention technique that had been used to cover the speed of the motors due to its simple structure as well as the easy understandable action of its parameters (Proportional, integral and derivative).

The field-oriented controller (FOC) is a common method operated to control the speed of the induction motor, where the motor behaves like a dc motor. A classical PI controller (that is fixed in the forward path for tracking the motor speed variation and gain values selection) is time consuming. To overcome this problem and in order to obtain the best gain value, the PI controlled genetic algorithm has 
been used to generate the parameters of the PI controller, as a result the time required to select the controller gain values is reduced [1].The motor speed can also be controlled by varying the stator voltage where the develop torque is directly proportional to the square of the applied voltage. The voltage source inverter (VSI) normally used to vary the supplied voltage of the induction motor, whereas FLC had been introduced to enhance the system performance based on direct torque and flux control methods [2].

The main problem for controlling the speed of IM is nonlinearity behavior of flux due to core saturation at high magnetization current specially at starting or during heavy motor loading. A direct torque control method (DTC) with FLC has been considered to improve the performance of motor operation. A dual FLC are used to get accurate performance for the develop torque and motor speed. A classical PI controller had been used to reduce the generated ripples with the develop torque and motor speed because of inverter harmonics [3]. A quantum lighting search algorithm (QLSA) with particle swarm optimization (PSO) had been studied in conjunction with backtracking search algorithm (BSA) to obtain the optimal values for the conventional PI and PID controllers. The optimized gain values are used to improve the induction motor speed control performance [4]. Among the different methods which are used to control the speed of the induction motor, the v/f method was considered the preferred one over others because of its ability to vary the motor speed over wide range compared with other types. A sinusoidal Pulse-Width Modulation (PWM) technique was used to feed the VSI. Due to their simple structure, the PI and FL controllers were used to investigate the operation performance of the IM in open loop system and closed loop system [5].

The PID controller had been used to reduce the effect of the disturbance associated with conventional controller. Also the speed of a three phase IM was controlled through a vector control based on FL technique. The obtained results show the fuzzy logic controller ability to overcome the problems which occur with the classical PID controller [6]. Neural network controller (NNC) have a wide range of applications in the field of electric machine's speed control. The operation of the IM is studied under the effect of external disturbance, the model explains the stability when the feed-forward neuro controller is used. Then a neuro-fuzzy controller is introduced to implement a vector controlled for the three phase IM. The results show the flexibility of the neuro-fuzzy controller in comparison with others [7].

FLC had been used to control the operation of a 3- $\Phi$ IM, through the selection of the duty cycle for the PWM. The output performance of the IM with the FL controller has been investigated under the disturbance of the applied external load torque [8] . Fuzzy logic controller also used with a sudden changes in load or speed conditions. Although scaler and vector control methods have been used to adjust the speed of machine, vector control method (which consist of direct and indirect field-oriented technique) has been widely used by many authors as an advanced method to obtain an accurate control for the speed of the motor and minimize the IM performance error [9]. An experimental real time control is considered in the process of modeling, simulating and implementing the structure of an IM system [10].

Due to its good quality output voltage and customized fast switching five stage NPC inverter is used by [11] to drive the induction motor using field orientation control strategy. This strategy is used to overcome the drawbacks (fast switching losses and high level harmonic with distorted output voltage) of the controlled two level inverter.The authors in [12] have suggest anew strategy based on the artificial neural network with direct torque control to reduce the effect of the problem (high current,flux and torque ripple as well as flux control at very low speed) which present in the conventional direct torque control. In reference [13] a predicative model reference adaptive system (PMRAs) rotor speed observer is proposed to produce the motor position more accurate and minimizes the tuning error of speed signal. The result of this observer is confirmed by simulation and showed a good dynamic performance in terms of rotor speed and position at low and zero speeds.

Different strategies for speed control of three phase IM have been used depending on the required application. First a classical methods are used to control the rotation of the motor for application that require small degree of accurate rotation. Voltage and frequency control (V/f) is considered the most common used method in this field to adjust the dynamic performance of the motor and also the best way to obtain a uniform flux during the operation. For industrial application where the change of speed and torque is an important factor, it is very necessary to have an efficient and accurate controller. Now days inelegant techniques like fuzzy, neural and genetic methodology are used to obtain a better controller performance to control the electric machines. In this paper the speed of the IM is controlled by varying the stator voltage. A a 3-phase voltage source inverter (VSI) with (SPWM) is used to control the motor supply voltage by controlling the applied firing angle to the power electronic devices. The width of triggering pulses on the drive circuit are tuned based on the difference between the reference and output signals. The error signal has been fed to the inputs of the designed PID and FL controllers with GA.

Int J Pow Elec \& Dri Syst, Vol. 10, No. 1, March 2019 : $117-127$ 


\section{MODELING OF THREE-PHASE INDUCTION MOTOR}

Two types (electrical and mechanical) of equations are involved in the modeling processes of the three phase IM. The electrical (1)-(6) represent the modeling of relation between the electrical stator parameters, rotor parameters and the mutual effect between them, whereas (7) clarify the modeling of the developed electrical torque relationship.

$$
\begin{aligned}
& V_{s}=i_{s} r_{s}+\frac{d \varphi_{s}}{d t}+j w_{s} \varphi_{s} \\
& V_{r}=i_{r} r_{r}+\frac{d \varphi_{r}}{d t}+j\left(w_{s}-w_{r}\right) \varphi_{r} \\
& \varphi_{s}=L_{s} i_{s}+L_{m} i_{r} \\
& \varphi_{r}=L_{r} i_{r}+L_{m} i_{r} \\
& L_{s}=L_{l s}+L_{m} \\
& L_{r}=L_{l r}+L_{m} \\
& T_{e}=T_{l}+J \frac{2}{P} \frac{d w_{r}}{d t}
\end{aligned}
$$

where:

$\mathrm{Vs}$, is and rs represent the stator voltage, current and resistance respectively. $\mathrm{Vr}$, ir and rr represent the rotor voltage, current and resistance respectively. Ls Lls, $\mathrm{Lr} \mathrm{Llr}$ and $\mathrm{Lm}$ are the stator, rotor and mutual inductances respectively. $\mathrm{J}$ is the all moment of inertia of the rotor and load, $\mathrm{P}$ is the number of pole pairs, TL is the load torque. The parameters of the IM that have been simulated in current paper are given in Table 1.

Table 1. The parameters of three phase induction motor

\begin{tabular}{llll}
\hline parameters & values & parameters & values \\
\hline $\mathrm{P}_{\text {in }}[\mathrm{KW}]$ & 4.028 & $\mathrm{~L}_{\mathrm{r}}[\mathrm{H}]$ & 0.00584 \\
$\mathrm{~V}[\mathrm{~V}]$ & 220 & $\mathrm{~L}_{\mathrm{m}}[\mathrm{H}]$ & 0.1722 \\
$\mathrm{f}[\mathrm{Hz}]$ & 50 & $\mathrm{R}_{\mathrm{s}}[\Omega]$ & 1.405 \\
$\mathrm{~L}_{\mathrm{s}}[\mathrm{H}]$ & 0.00584 & $\mathrm{R}_{\mathrm{r}}[\Omega]$ & 1.395 \\
$\cos \phi_{\mathrm{n}}$ & 0.8 & $\mathrm{~J}_{\mathrm{n}}\left[\mathrm{kg} \cdot \mathrm{m}^{2}\right]$ & 0.065 \\
$\mathrm{~F}_{\mathrm{c}}[\mathrm{N} . \mathrm{m} . \mathrm{s} / \mathrm{rd}]$ & 0.00298 & $\mathrm{P}$ & 4 \\
\hline
\end{tabular}

\section{SPWM METHOD}

PWM methods have usually used in voltage source and current source inverter to fed AC motor drives. In this work, a sinusoidal pulse width modulation (SPWM) technique has been selected to generate the switching signals.. This method is used in many types of industrial applications. While the control variety for its modulation index is moderately fine, SPWM is a modest method and has well transient response. A high-frequency triangle carrier signal is compared with a three phase sinusoidal signal from supply frequencies as exposed in Figure 1.The power plans in separately phase are exchanged on at the connection points of the sine wave and triangle wave. The modulation index which is given by the ratio of the carrier amplitude to sinusoidal signal amplitude is used to decide the value of the output voltage.

$$
\mathrm{Mi}=\frac{\mathrm{A}_{\mathrm{e}}}{\mathrm{A}_{\mathrm{r}}}
$$

Where Ae is the carrier amplitude and Aris the sinusoidal signal amplitude. 


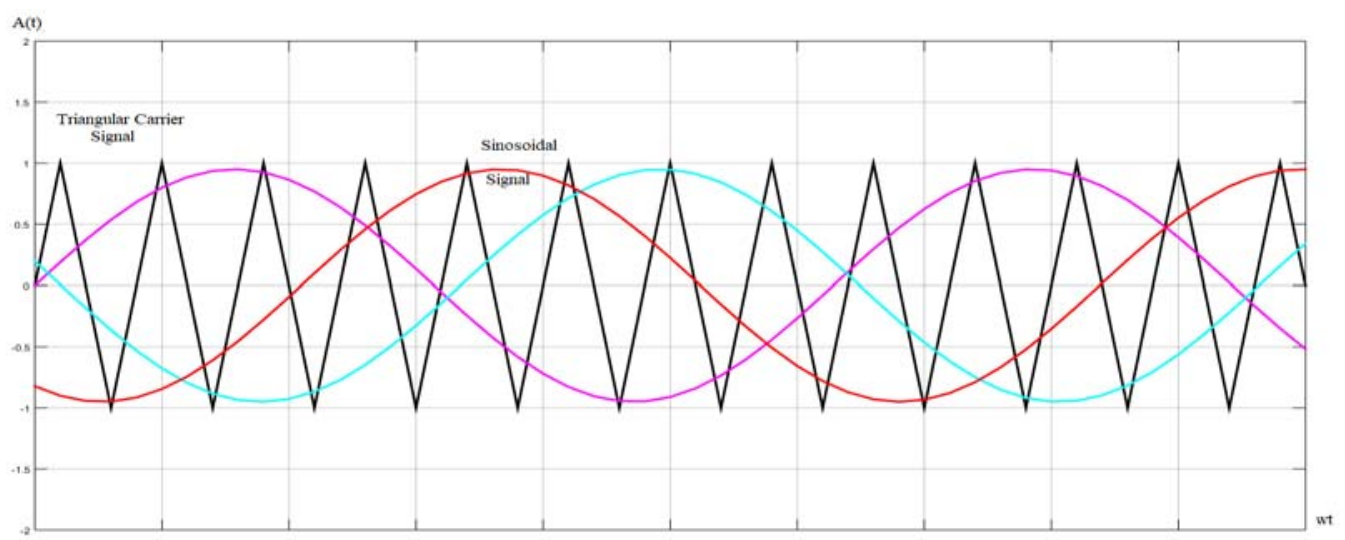

Figure 1. SPWM wave form

\section{THE PID CONTROLLER}

A convention PID controller plays an important role in various control processes. It is mainly used to reduce or eliminate the steady-state error of the system response and as a result it improves the dynamic behavior of the system. So the proportional part of the controller enhances the transient step response of the system (rising time, steady state error), the derivative part of the controller increases a limited zero to the open - loop plant transfer function and improves the transient response( overshoot, rising time, settling time and peak time). While the integral part adds a pole at the origin, which add one to the system type and thus the steady-state error for a step input function will be reduced to zero. The general formula for the PID controller is defined as:

$$
\mathrm{PID}=\mathrm{KP}+\mathrm{KI} / \mathrm{S}+\mathrm{KDS}
$$

where the control parameters $\mathrm{KP}, \mathrm{KI}$ and $\mathrm{KD}$ are the proportional factor, the integral factor and the derivative factor correspondingly. The block diagram of PID controller as shown in Figure 2.

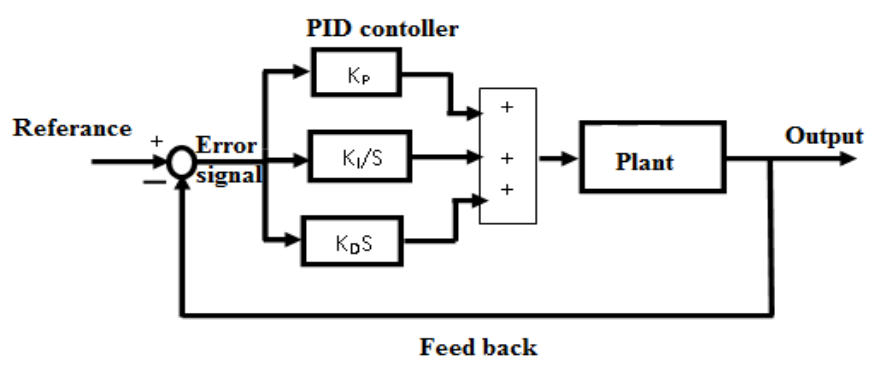

Figure 2. The block diagram of PID controller

Different methods have been used to calculate the controller parameters like trial and error method, Ziegler-Nichols method and another modern algorithms [1], [14].

\section{DESIGN OF FUZZY LOGIC CONTROLLER (FLC)}

In this paper the fuzzy logic controller (FLC) is carefully designed with two inputs and one output. The error $\mathrm{e}(\mathrm{t})$ and change of error $\Delta \mathrm{e}(\mathrm{t})$ are considered as input signal to this FLC. The output signal has been feed to the 3-phase VSI to control the applied voltage to the IM terminals. The linguistic variables (N,NB,NS,Z,P, PS, PB) and the fuzzy rules are defined and summarized in Table 2. The triangular member ship functions are chosen to represent the input (error and change in error signals) for this fuzzy logic controller. An appropriate scale ranges (-100 to 100 for $\mathrm{e}(\mathrm{t})$ and -50 to 50 for $\Delta \mathrm{e}(\mathrm{t}))$ are selected.

Int J Pow Elec \& Dri Syst, Vol. 10, No. 1, March 2019 : 117 - 127 
Table. 2. Fuzzy logic controller rule base

\begin{tabular}{llllllll}
\hline $\mathrm{e} / \Delta \mathrm{e}$ & $\mathrm{NB}$ & $\mathrm{N}$ & $\mathrm{NS}$ & $\mathrm{ZE}$ & $\mathrm{PS}$ & $\mathrm{P}$ & $\mathrm{PB}$ \\
\hline $\mathrm{NB}$ & $\mathrm{NB}$ & $\mathrm{NB}$ & $\mathrm{NB}$ & $\mathrm{NB}$ & $\mathrm{N}$ & $\mathrm{NS}$ & $\mathrm{ZE}$ \\
$\mathrm{N}$ & $\mathrm{NB}$ & $\mathrm{NB}$ & $\mathrm{NB}$ & $\mathrm{N}$ & $\mathrm{NS}$ & $\mathrm{ZE}$ & $\mathrm{PS}$ \\
$\mathrm{NS}$ & $\mathrm{NB}$ & $\mathrm{NB}$ & $\mathrm{N}$ & $\mathrm{NS}$ & $\mathrm{ZE}$ & $\mathrm{PS}$ & $\mathrm{P}$ \\
$\mathrm{ZE}$ & $\mathrm{NB}$ & $\mathrm{N}$ & $\mathrm{NS}$ & $\mathrm{ZE}$ & $\mathrm{PS}$ & $\mathrm{P}$ & $\mathrm{PB}$ \\
$\mathrm{PS}$ & $\mathrm{N}$ & $\mathrm{NS}$ & $\mathrm{ZE}$ & $\mathrm{PS}$ & $\mathrm{P}$ & $\mathrm{PB}$ & $\mathrm{PB}$ \\
$\mathrm{P}$ & $\mathrm{NS}$ & $\mathrm{ZE}$ & $\mathrm{PS}$ & $\mathrm{P}$ & $\mathrm{PB}$ & $\mathrm{PB}$ & $\mathrm{PB}$ \\
$\mathrm{PB}$ & $\mathrm{ZE}$ & $\mathrm{PS}$ & $\mathrm{P}$ & $\mathrm{PB}$ & $\mathrm{PB}$ & $\mathrm{PB}$ & $\mathrm{PB}$ \\
\hline
\end{tabular}

$\mathrm{Z}=$ zero, $\mathrm{N}=$ nagetive, $\mathrm{NB}=$ nagetive big, $\mathrm{NS}$ = nagetive small

$\mathrm{P}=$ positive, $\mathrm{PB}=$ positive $\operatorname{big}, \mathrm{PS}=$ positive small

\section{GENETIC ALGORITHM (GA)}

Genetic algorithm has a wide application in control process because of its ability to work as an optimization tool instead of the conventional control type. GA technique is considered as an adaptive method for searching the solution of difficult problems where it can be combined with other intelligent methods. It consists of many solution steps like, Initial population, Crossover, Selection, Mutation, Fitness function and Stopping criteria [1], [15]. Due to the drawback (long time to select the gain values) of conventional methods, GA has been effectively used to determine the controller parameters value. GA is used in the current work to select the optimized (error and change of error) gain values of the fuzzy logic controller. Table 3 shows the selected value of the parameters that are used in this GA.

Table 3. Genetic algorithm parameters

\begin{tabular}{cc}
\hline Parameters & Values \\
\hline Number of string (population) & 40 \\
Number of generations & 50 \\
Probability of crossover $\left(\mathrm{P}_{\mathrm{c}}\right)$ & 1.0 \\
Probability of mutation $\left(\mathrm{P}_{\mathrm{m}}\right)$ & 0.01 \\
\hline
\end{tabular}

\section{HYBRID CONTROLLER DESIGN}

The classical try and error method(which is applied to select the parameter values of the PID controller and FL controller gains) requires a long computation time and cannot produce the optimal results. The genetic optimization algorithm can be designed and programed to get an optimal controller parameters. This algorithm can be used to search the best PID and FL controller parameters gain value, which leads to a better performance control system and eliminate the long computation time for gains determination. The optimization genetic algorithm is programed using MATLAB software package. The steps of implementing the hybrid algorithm of PID with FL controller are explained by the flowchart shown in Figure 3.

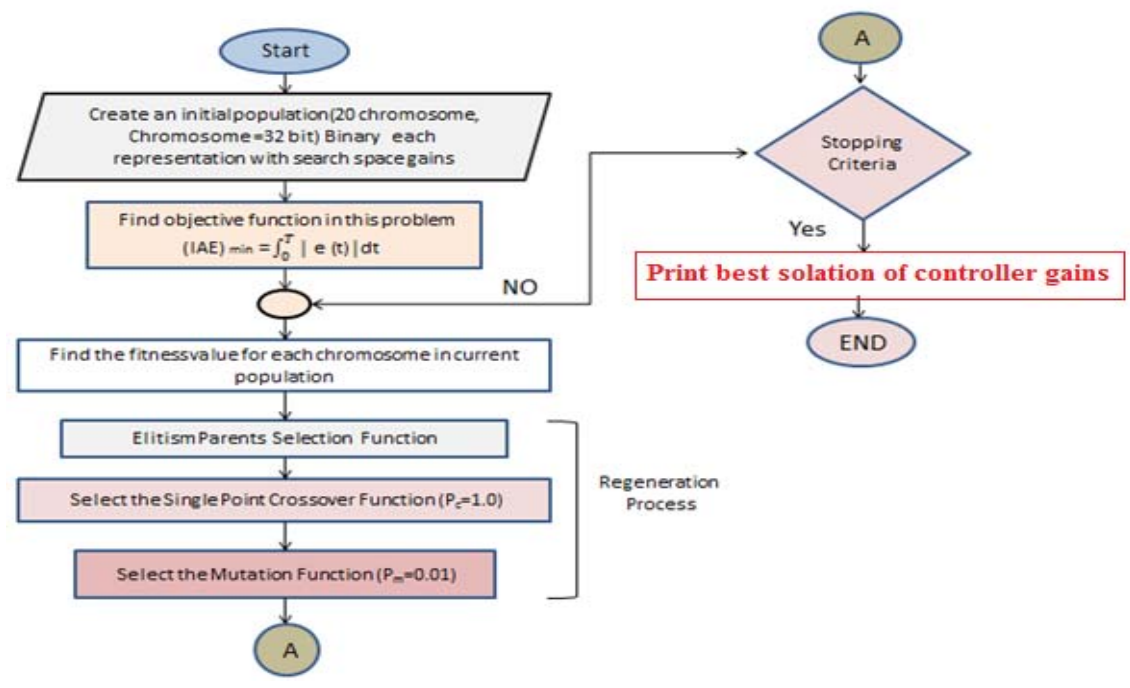

Figure 3. Flowchart of hybrid controllers 


\section{SIMULATION RESULTS AND ANALYSIS OF THE PROPOSED HYBRID CONTROL SYSTEM}

Based on MATLAB/Simulink software a 3-phase IM driven by VSI has been modeled and simulated as shown in Figure 4. Two types PID and FL of classical controller have been used in the feedback loop to adjust the dynamic performance parameters (develop torque and rotor speed) of the induction motor. A genetic algorithm has been introduced to speed up the gain selection processes and improve the behavior of the conventional PID controller as well as adjusting the gains at FL controller input. The induction motor has been simulated under no load and then different load torque values have been applied on the shaft of the tested motor.

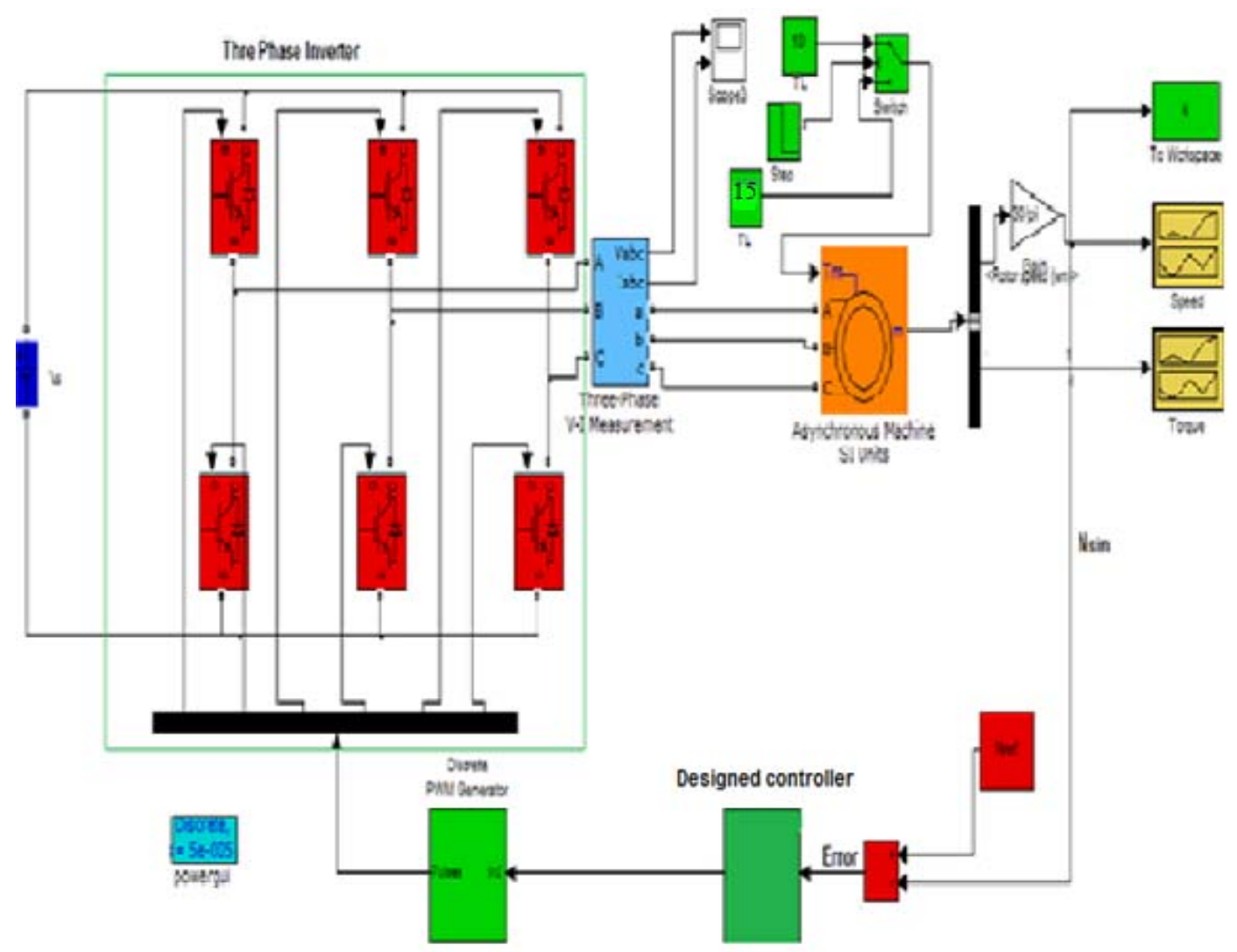

Figure .4. Three phase IM fed by VSI system block diagram

The open loop simulation results of the developed torque, stator and rotor currents and motor speed are shown in Figures 5-6 for $(\mathrm{TL}=0,5$ and $15 \mathrm{Nm})$ at the time $(0,1$ and 2 second) respectively, these show the dynamic characteristic of the tested motor under this loading criteria. Under closed loop, the different between the actual motor speed signal and reference speed signal is fed to the input of the classical PID controller. The error signal has been processed by the controller and used as a control signal to decide the amplitude and intervals of the PWM output. The reference speed are selected to be equal to 104.66, 125.56 and $146.53 \mathrm{rad} / \mathrm{sec}$. Figures 7-8 show, the motor speed, stator current ,rotor current and electromagnetic torque under the effect of the conventional controller. For the same above loading conditions and at the same time intervals, Figures 9-10 show the simulation results improvement in the performance of the IM under the effect of the proposed intelligent FL controller. Finally in order to reduce the computation time of the controller gains and to get the optimal gain values of the classical PID and FLC a genetic algorithm has been used. Figures 11-12 and Figures 13-14 clarify the improvement in system performance due to the application of GA with the controllers PID and FL respectively.

Int J Pow Elec \& Dri Syst, Vol. 10, No. 1, March 2019 : 117 - 127 


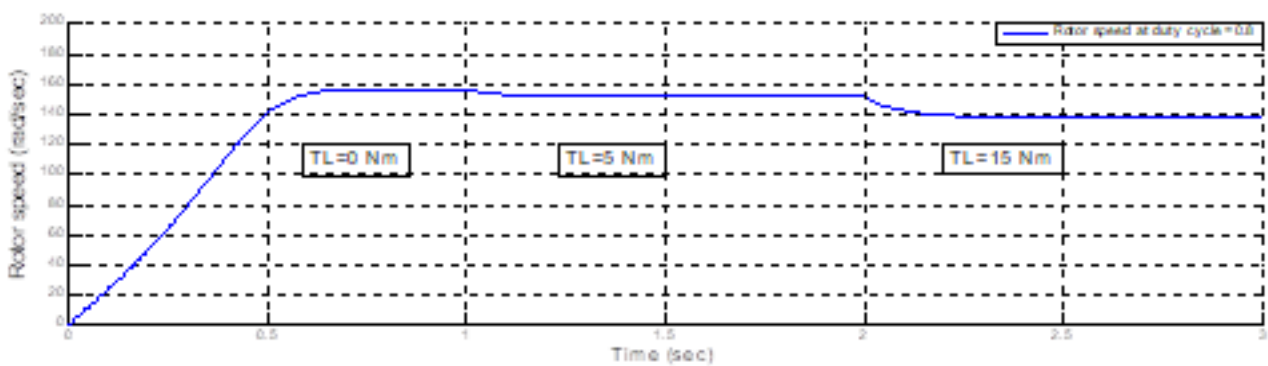

Figure 5. Open loop speed respone under various load torque

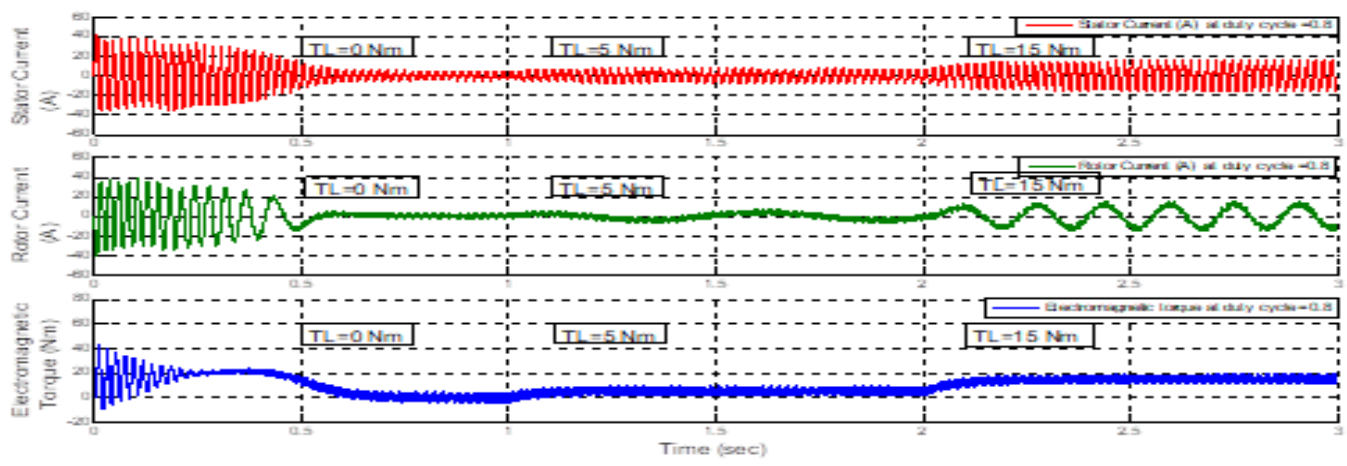

Figure 6. Open loop stator, rotor current and electromagnetic torque

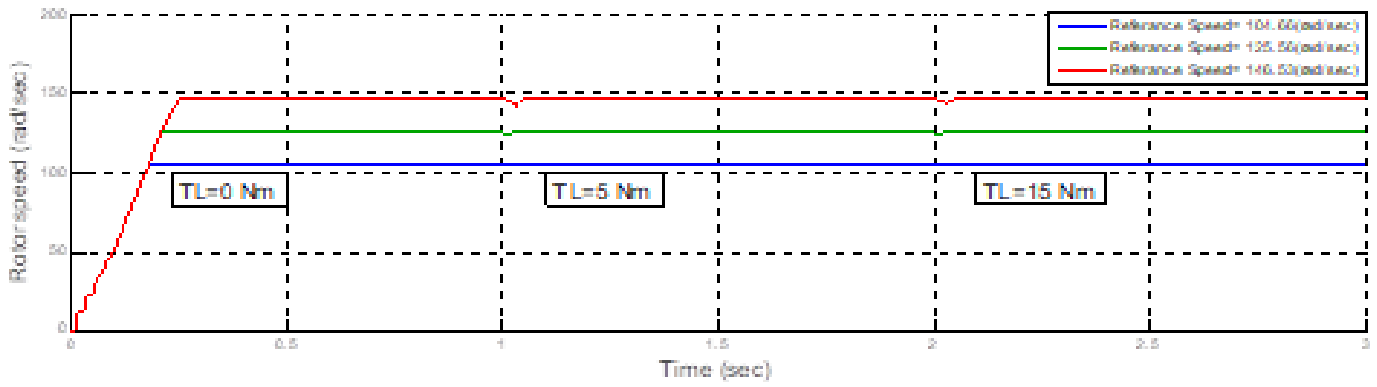

Figure 7. Speed respones with PID controller

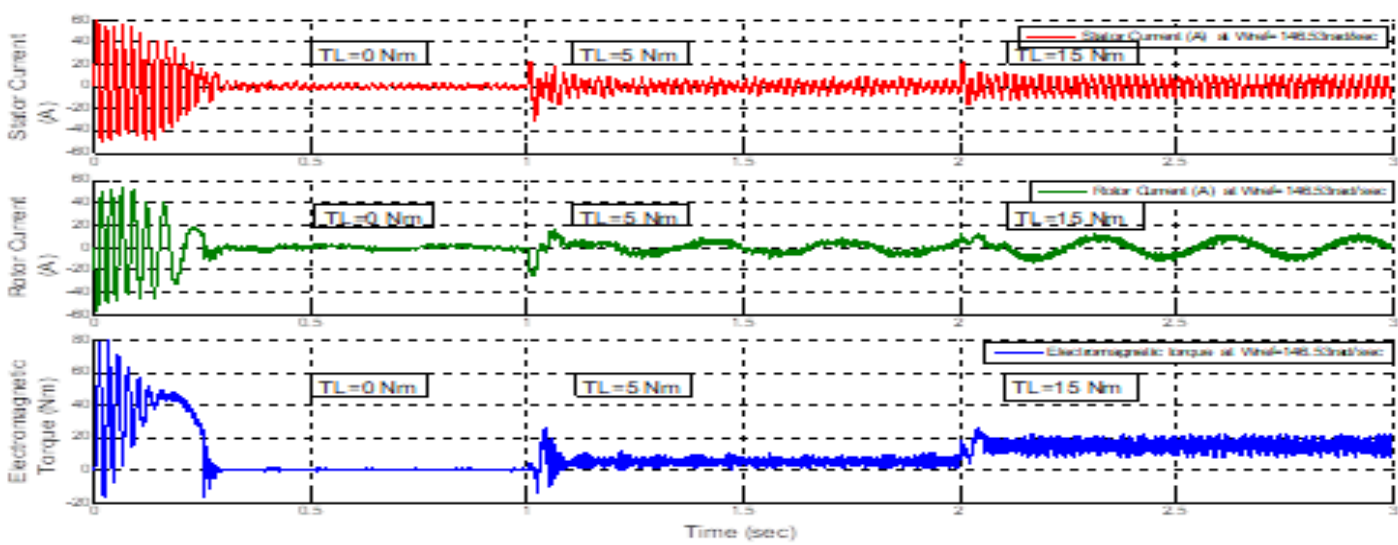

Figure 8. Stator, rotor currents and electromagnetic torque with PID controller and reference speed $146.53 \mathrm{rad} / \mathrm{sec}$ 


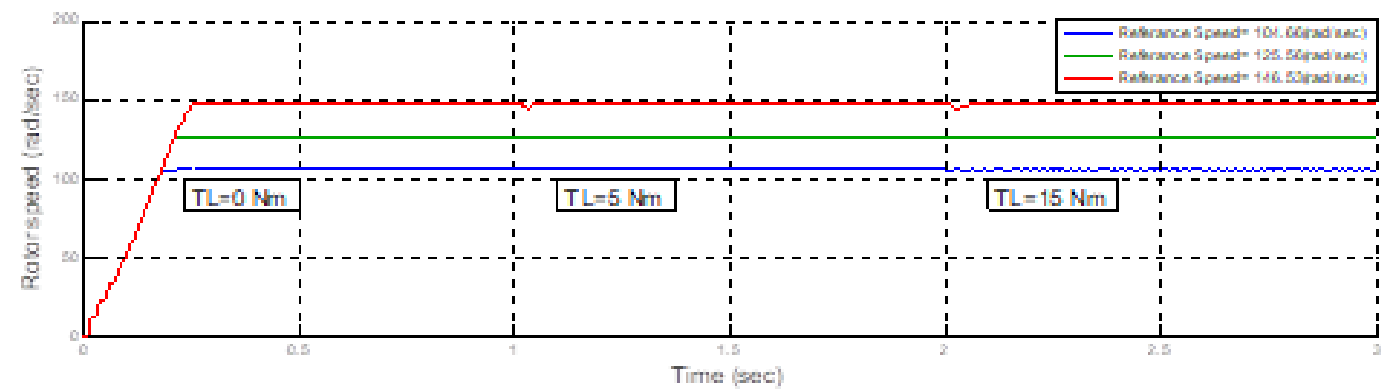

Figure 9. Speed respones with FL controller

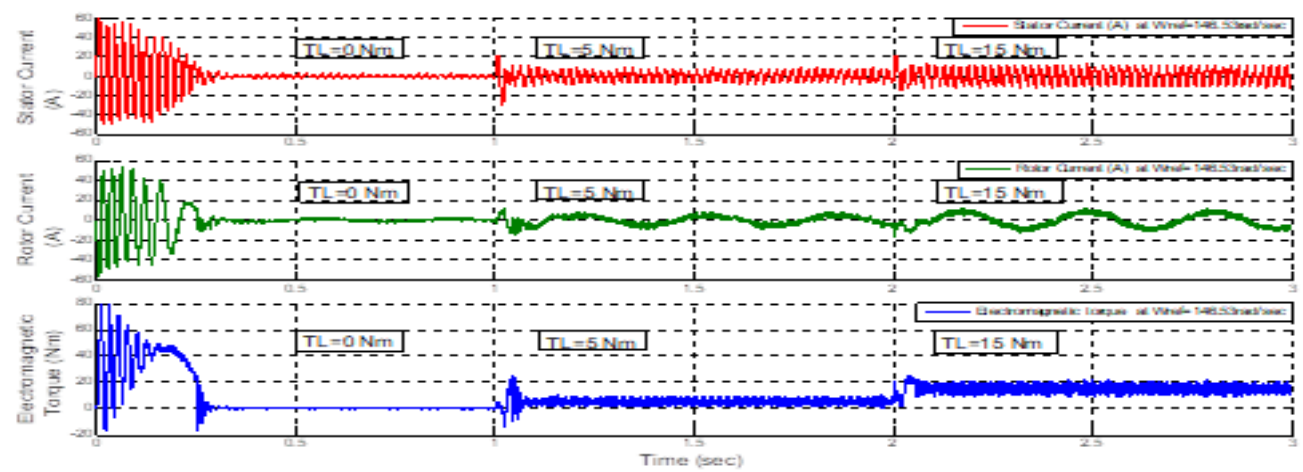

Figure 10. Stator, rotor currents and electromagnetic torque with FL controller and reference speed $146.53 \mathrm{rad} / \mathrm{sec}$

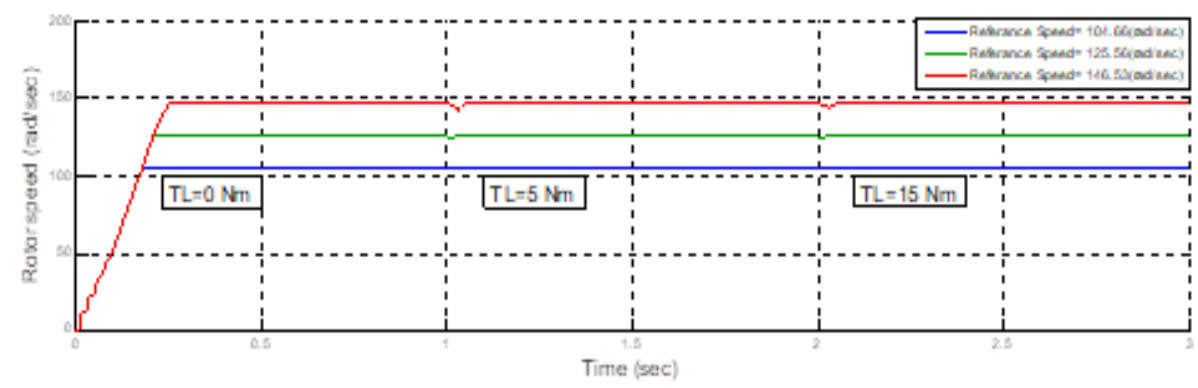

Figure 11. Speed respones with hybird PID/GA controller

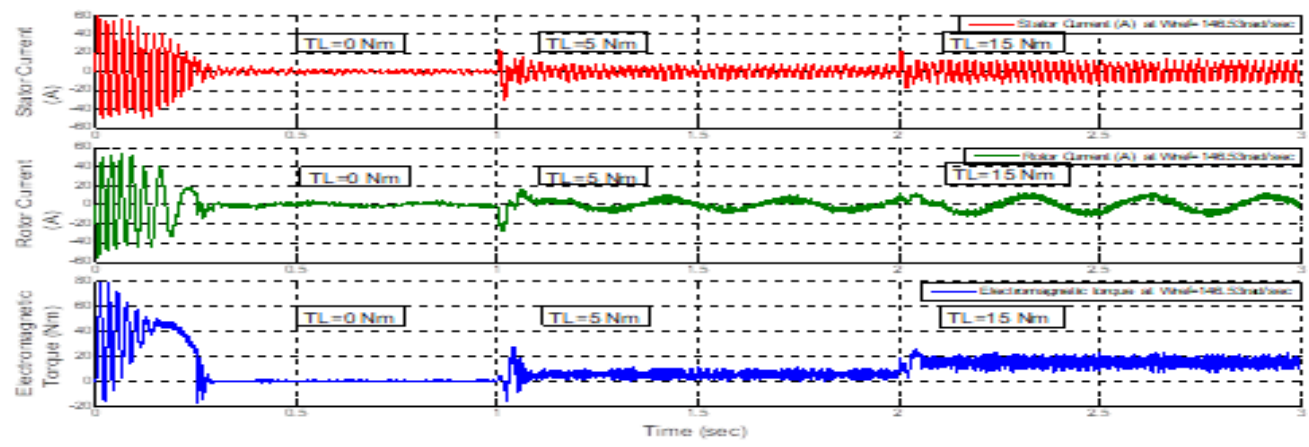

Figure 12. Stator, rotor currents and electromagnetic torque with hybird PID/GA controller and reference speed $146.53 \mathrm{rad} / \mathrm{sec}$ 


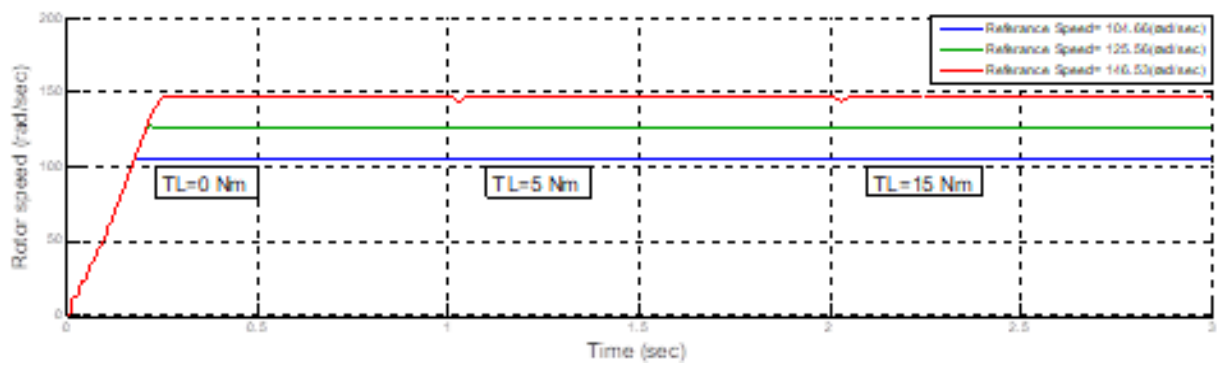

Figure 13. Speed respones with hybird FL/GA controller

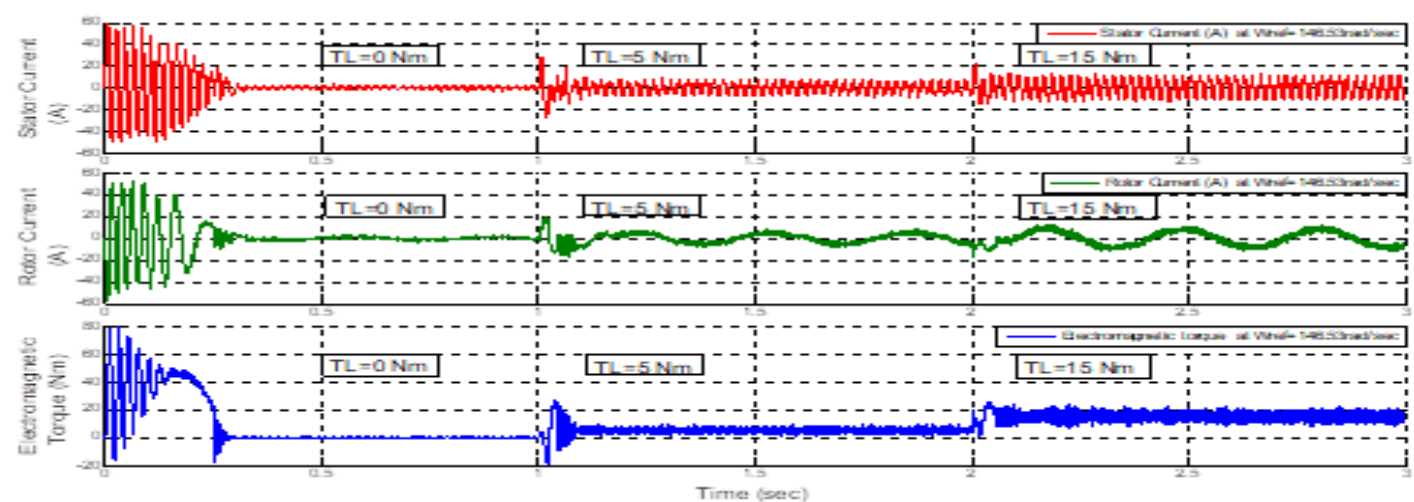

Figure 14. Stator, Rotor Currents and electromagnetic torque with hybird FL/GA Controller and reference speed $146.53 \mathrm{rad} / \mathrm{sec}$

A performance comparision among the results of open loop system, closed loop system under PID, FL, hybrid PID/GA and hybrid Fl/GA controllers are shown in Table 4. The theortical torque from (7) and simulated torque are comparision of open loop system, closed loop system under hybrid F1/GA controllers are shown in Tables 5 and 6 . The obtained simulation results show that the FL based GA controller gives the best system performance in comparison with other controllers.

Table 4. The phase induction motor comparative results at $146.53 \mathrm{rad} / \mathrm{sec}$

\begin{tabular}{ccccccc}
\hline Designed/ system & $\begin{array}{c}\text { Steady state error } \\
(\mathrm{ess})[\%] \text { when TL } \\
\text { (15Nm }\end{array}$ & $\begin{array}{c}\text { Peak Over } \\
\text { shoot (p.o.s) } \\
{[\%]}\end{array}$ & $\begin{array}{c}\text { Setlling time } \\
\text { (tss) [s] }\end{array}$ & $\begin{array}{c}\text { Rising time } \\
\text { (tr) [s] }\end{array}$ & $\begin{array}{c}\text { Delay time } \\
\text { (td) [s] }\end{array}$ & $\begin{array}{c}\text { System } \\
\text { efficincy [\%] }\end{array}$ \\
\hline $\begin{array}{c}\text { Open loop system } \\
\text { at duty cycle of } \\
\text { converter=50\% }\end{array}$ & 11.2 & 0 & 00.56 & 00.385 & 00.226 & 81.5 \\
$\begin{array}{c}\text { Close loop system } \\
\text { with PID }\end{array}$ & 0.24 & 0.615 & 00.285 & 00.238 & 00.1405 & 95.25 \\
$\begin{array}{c}\text { Close loop system } \\
\quad \text { with FL }\end{array}$ & 0.134 & 0.07 & 00.284 & 00.239 & 00.142 & 95.43 \\
$\begin{array}{c}\text { Close loop system } \\
\text { with Hybrid } \\
\quad \text { PID/GA }\end{array}$ & 0.007 & 0.27 & 00.278 & 00.227 & 00.133 & 95.87 \\
$\begin{array}{c}\text { Close loop system } \\
\text { with Hybrid FL/GA }\end{array}$ & 0.006 & 0.008 & 00.275 & 00.226 & 00.138 & 95.92 \\
\hline
\end{tabular}

Table 5. A brief comparison between theoretical and simulated torque at different operation conditions for open loop system

\begin{tabular}{ccccc}
\hline Time $(\mathrm{s})$ & $\begin{array}{c}\text { Steady state speed } \\
(\mathrm{rad} / \mathrm{s})\end{array}$ & $\begin{array}{c}\text { Applied torque } \\
{[\mathrm{N} . \mathrm{m}]}\end{array}$ & $\begin{array}{c}\text { Theoretical developed torque } \\
{[\mathrm{N} . \mathrm{m}]}\end{array}$ & $\begin{array}{c}\text { Simulated developed torque } \\
{[\text { N.m] }]}\end{array}$ \\
\hline 0.8 & 157 & 0 & 0 & 0.147 \\
1.5 & 152 & 5 & 5 & 5.113 \\
2.5 & 136 & 15 & 15 & 15.120 \\
\hline
\end{tabular}

Performance evaluation of a hybrid fuzzy logic controller based on genetic algorithm ... (Ahmed J. Ali) 
Table 6. A brief comparison between theoretical and simulated torque at different operation conditions for with FL/GA

\begin{tabular}{ccccc}
\hline Time $(\mathrm{s})$ & $\begin{array}{c}\text { Steady state speed } \\
(\mathrm{rad} / \mathrm{s})\end{array}$ & $\begin{array}{c}\text { Applied torque } \\
{[\mathrm{N} . \mathrm{m}]}\end{array}$ & $\begin{array}{c}\text { Theoretical developed torque } \\
{[\mathrm{N} . \mathrm{m}]}\end{array}$ & $\begin{array}{c}\text { Simulated developed torque } \\
{[\text { N.m] }}\end{array}$ \\
\hline 0.8 & 157 & 0 & 0 & 0.183 \\
1.5 & 152 & 5 & 5 & 5.126 \\
2.5 & 136 & 15 & 15 & 15.132 \\
\hline
\end{tabular}

Also from the Table 5, one can conclude that the performance of the open loop system has high values of steady state time, state steady error, delay time and rising time values. The closed loop system with FL or PID controller has a better performance compared with open loop system. Also in comparison with the other controllers the obtained results show that the hybrid FL with GA controller has the best improvement in the system performance.

\section{CONCLUSION}

Three-phase inverter have been used to convert DC voltage to an AC voltage and used to drive a 3phase IM. The FL and PID controllers are designed and their gain values computed using try and error method while the genetic algorithm is introduced to compute the classical PID and the proposed FL controllers gain values, the output of FL controller is used to decide the value of the PWM modulation index and control the operation of the three phase inverter gates as drive for the IM to improve its performance. Different controller (FL, PID, PID/GA and the proposed FL/GA) techniques are used to control the system output speed response and enhance its performance. These techniques for controllers are modeled and the simulated under different operating conditions for open loop and closed loop systems The simulation results show that the proposed FL/GA has the best efficiency (95.92\%) performance with an improvement of $14.42 \%$ with respect to the open loop system performance. Also the proposed controller shows an enhance efficiency gains of $0.67 \%, 0.49 \%$ and $0.05 \%$ with respect to the PID FL and PID/GA respectively. Results show clearly improvement in the operation of the induction motor with a hybrid FL/GA algorithm control technique. The simulation results show goal consistory with the theoretical results according to the mathematical formula in (7) which describe behavior of the develop torque with the different applied torque of different times.

\section{REFERENCES}

[1] M'hamed Chebre, Abdelkader Meroufel, Yessema Bendaha, "Speed Control of Induction Motor Using Genetic Algorithm-based PI Controller," Acta Polytechnica Hungarica Journal, vol. 8, pp.141-153, 2011.

[2] A. Lokriti, Y. Zidani and S. Doubabi, "Fuzzy logic control contribution to the direct torque and flux control of an induction machine,"2011 International Conference on Multimedia Computing and Systems, Ouarzazate, pp. 1-6, 2011.

[3] M. Moustafa Hassan and M. Mahmoud Ismail, "Using fuzzy logic algorithm for improvement of DTC three level inverter performance considering saturated model of induction motor,"8th IEEE Symposium on Diagnostics for Electrical Machines, Power Electronics \& Drives, Bologna, pp. 503-510, 2011.

[4] J. A. Ali, M. A. Hannan and A. Mohamed, "Optimized speed controller for induction motor drive using quantum lightning search algorithm,"2016 IEEE International Conference on Power and Energy (PECon), Melaka, pp. 511-516, 2016.

[5] P. M.Menghala, A Jaya Laxmib, "Fuzzy Based Real Time Control of Induction Motor Drive," International Conference on Computational Modeling and Security, pp. 228-235, 2016.

[6] H.Sathishkumar, S.S.Pathasarathy, "A novel fuzzy logic controller for vector controlled induction motor drive," 2017 International Conference on Alternative Energy in Developing Countries and Emerging Economies, Bankok, pp. 686-691, 2017.

[7] H.Sathishkumar, S.S.Pathasarathy, "A novel fuzzy logic controller for vector controlled induction motor drive," 2017 International Conference on Alternative Energy in Developing Countries and Emerging Economies, Bankok, pp. 698-703, 2017.

[8] Sudheer H, Kodad S.F, Sarvesh B, "Improvement in direct torque control of induction motor for wide range of speed operation using fuzzy logic," Journal of Electrical System and Information Technology, pp.1-16, 2017.

[9] M.A. Hannan, Jamal A. Alib, Azah Mohamedc, Aini Hussain, "Optimization techniques to enhance the performance of induction motor drives: A review," Renewable and Sustainable Energy Reviews, vol. 81, p. 16111626, 2018.

[10] A. Hamed and A. Hazzab, "Modeling and Real-Time Simulation of Induction Motor Using RT-LAB," International Journal of Power Electronics and Drive System (IJPEDS), vol. 9, pp. 1476-1485, 2018.

Int J Pow Elec \& Dri Syst, Vol. 10, No. 1, March 2019 : 117 - 127 
[11] Mouna Es-Saadi, Mohamed Khafallah And Hamid Chaikhy, "Using the Five-Level NPC Inverter to Improve the FOC Control of the Asynchronous Machine, "International Journal of Power Electronics and Drive System (IJPEDS), vol. 9, pp. 1457-1466, 2018.

[12] Zineb Mekrini and Seddik Bri, "High-Performance using Neural Networks in Direct Torque Control for Asynchronous Machine," International Journal of Electrical and Computer Engineering (IJECE), vol. 8, pp. 10101017, 2018.

[13] Moustafa Zair and Abdeldejbar Hazzab, "MRAS Speed Sensorless Vector Control of Induction Motor Drives Using Predictive Adaptation Mechanism", International Journal of Power Electronics and Drive System (IJPEDS), vol. 9, pp. 1523-1533, 2018.

[14] Katsuhiko Okata "Modern Control Engineering," fifth edition, Prentice Hal, 2010.

[15] Kim, D. H., Abraham, A., Cho, J. H. "A hybrid genetic algorithm and bacterial foraging approach for global optimization," Information Sciences, vol. 177, pp. 3918-3937, 2017.

\section{BIOGRAPHIES OF AUTHORS}

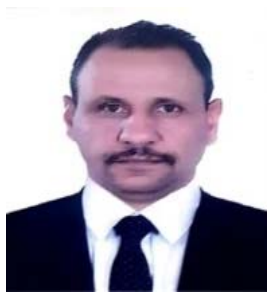

Dr. Ahmed J. is a lecturer at Dep. of power engineering technology/ Engineering Technical College/Mosul. He has get BSc.and Msc. From Al-Thechnologia Unversity/ Baghdad In 1995 and 2004 respectively in Electrical Engineering. He has finish his Ph.D. in Electrical Machines from university of Mosul in 2012. He has been Bunsvuer Univesity /Germany in Research Scholarship for 6 months during his Ph.D. studying period.His filed of work concentrate on Adaptive and Intelgent control Systems, Electric machines Designe and Drives. Now he is Head Dep. of Power Engineering Technology at Engineering Technical College/Mosul.

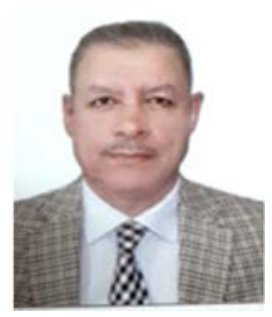

Dr. Ziyad K. Farej is a lecturer and has BSc. in Electronic System Eng. from Cranfield University/UK with honor degree in 1989. MSc. in Spread Spectrum System/FH from Mosul University in 2003. Ph.D. in Computer and Communication Networks (Mesh Network based WIMAX IEEE 802.16 Standard technology) from Mosul University in 2012 with excellent grade. He has been to Salford Greater Manchester University/UK in Research Scholarship for 6 months during his Ph.D. studying period. Wireless Computer and Communication Networks, Ad-hoc WLAN, WSN, 802.11 Wi-Fi, 802.16 Wi-MAX, Spread Spectrum, CDMA, OFDM and MIMO Systems, Digital Filter, FPGA and Controllers. Now he is a member of the Scientific Committee at Engineering Technical College/Mosul.

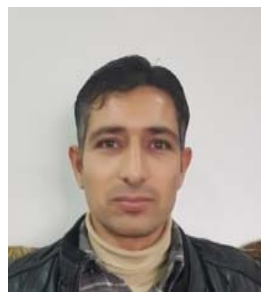

Nashwan S.Sultan. B.Sc in Power Technical Engineering/ Northern Technical University in 2008 with grade very Good with woner degree. MSc in Electrical Engineering /Control Engineering from Electrical Eng. Dept./College of Engineering /University of Mosul in 2013 with grade very Good. Currently he is an assisting lecturer at the Department Power Technical Engineering/ Engineering Technical College/Mosul. 